\title{
The Tourism Management in the Participatory Organic Farming Way at Bankamkhonta Village, Yasothon Province, Thailand
}

\author{
Suthira Mankong ${ }^{1}$, Amorn Chaisaen ${ }^{2}$, Sahakuan Saentaweesook ${ }^{3}$ \\ ${ }^{1,2,3}$ Yasothon Community College, Yasothon, THAILAND
}

\begin{abstract}
The objectives of this research were to study the potential of Bankamkhonta community in organizing communitybased tourism on the organic farming way and to find a way to develop Bankamkhonta community as a community-based tourism destination in the organic farming way by using the participatory action research process. Conducting this research used group discussions, field visits, workshops, and learning exchanges from successful communities in tourism management. Content analysis is a method of analyzing research data. The results showed that Bankamkhonta community is a community with potential for community-based tourism management on the organic farming way because it is an area that already has organic farming and is a community where people gather to do social activities about continuous and concrete organic farming. The community is able to organize tourism that focuses on activities that tourists experience and understand the value of organic farming or organic agrotourism and may upgrade such tourism to health and wellness tourism in the future.
\end{abstract}

KEYWORDS: Community-based Tourism, Organic Farming, Participatory Action Research, Tourism

\section{INTRODUCTION}

At present, each country focuses on the development of domestic tourism to have a higher potential in order to compete with other countries in the world's tourism market. Because tourism is a tool to develop the country's economy. Agro-tourism is therefore an important option (Khermkhan, 2018; Maraphot \& Somboon, 2016; Udomsilp, et al., 2020; Maneerot, 2017). Agro-tourism plays an important role in the Thai economy because it involves many sectors of production (Khermkhan, Mankeb, \& Patthirasinsiri, 2018). If considering the policies of the public and private sectors under the Thai government's Pracharath working group, it has supported agro-tourism under the "Amazing Thai Test" project, which is a project that encourages foreign tourists to consume more Thai food and fruit. The Office of Agricultural Economics of Thailand estimates that the measure will increase agro-tourism growth to 8-10\% per year, which will result in agro-tourism income worth 13.8 billion baht, coming from foreign tourists about 12,000 million baht and about 1,860 million baht for Thai tourists. In addition, the changing behavior of tourists who turned more attention to agricultural tourism. Modern tourists want to interact with local people and want to get involved and learn new experiences in the way of life of people in the community and there is an interaction between the owner of the wisdom and the tourists by giving opportunities to exchange experiences with the local community (Manirochana \& Nambuddee, 2020). This has led Asian countries to turn their attention to agro-tourism, starting with a focus on the resources that each country has. Then those countries have developed into a tourist attractions that can attract a large number of tourists to the country. Countries have planned to implement agricultural tourism strategies, including Thailand. At present, Thailand has more than 1,215 agro-tourism sites, comprising 969 community tourist sites, 87 government tourism sites, and 163 agricultural tourism development learning centers. Bankamkhonta has high cultural and agricultural capital. There is a strong group of community enterprises that are integrated into organic farming. Reflecting on the opinions of the participants in the New Wave Leadership Development Program in the Thai government project, it was suggested that Bankamkhonta should have an eco-tourism management with an emphasis on organic agriculture. This action is to give tourists the opportunity to live in order to experience and learn about organic farming such as organic rice farming, fish farming in organic rice fields, organic vegetable and fruit planting, which the community is interested in learning and doing tourism management. For that reason, the research team is interested in studying and assessing the community's potential in managing community-based tourism based on organic farming practices, as well as suggesting guidelines for development towards sustainable organic tourism management. 


\section{International Journal of Current Science Research and Review}

ISSN: 2581-8341

Volume 04 Issue 09 September 2021

DOI: 10.47191/ijcsrr/V4-i9-03, Impact Factor: 5.825

IJCSRR@ 2021

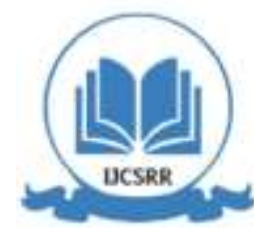

Www.ijcsrr.org

\section{LITERATURE REVIEW}

The office of Tourism Development, Department of Tourism, Ministry of Tourism and Sports (2015) defines agro-tourism that means tourism that focuses on learning the way of agriculture by allowing tourists to participate in activities to learn about agriculture and way of life, culture, traditions, and the use of available resources to take advantage of generating income for families and communities. Agro-tourism refers to tourism that focuses on learning the agricultural way of rural people through the participation of tourists and generate income for the community and farmers, including tourists to enjoy agricultural activities and have a sense of conservation of the environment (Chaisaengprateep, 2014). Agro-tourism and local wisdom will be tools for conservation along with sustainable tourism. It also gives more meaning to agro-tourism as a tourist attraction that enhances agricultural knowledge along with leisure and entertainment (Khermkhan, 2018; Udomsilp, et al., 2020). The environmentally friendly tourism management and the ecosystem affect the sustainability of the environment, society, culture, and community because of participating in the co-thinking, co-planning, co-operation, and collective benefits of the community. Tourism is a tool for community development and a tool to promote community strength in tourism resource management (Maneerot, 2017). The study of Khermkhan, Mankeb, and Patthirasinsiri (2018) presented a study on the supply chain of agro-tourism as shown in Figure 1.

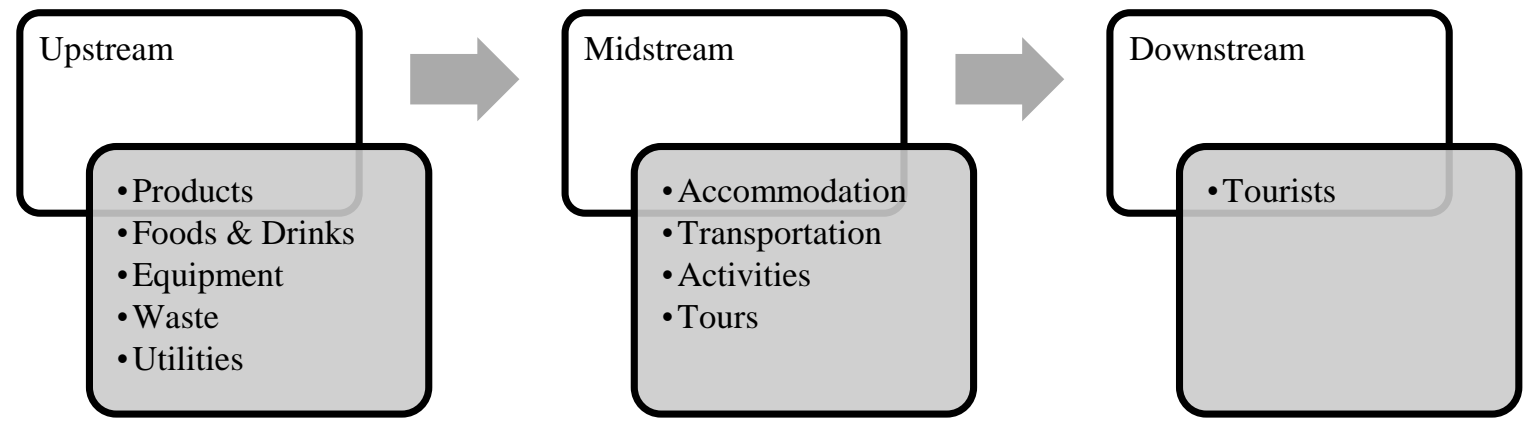

Figure 1. Supply chain management of Agro-tourism

Tourists can experience the agricultural way of life, traditions, and culture of the local community including participating in a variety of agricultural activities to build skills, exchange agricultural knowledge, has entertainment in various ways and can buy agricultural produce and community products back to their homeland. It is consistent with the concept of Na Songkhla (2011) that agro-tourism is tourism that aims to provide tourists with opportunities to learn about the lifestyles of farmers, the environment, and the natural and local culture, getting enjoyment and relaxation. And in terms of farmers, agro-tourism is the use of agricultural resources and culture as tourism resources, focusing on the well-being of rural communities and earning more along with the conservation of agricultural resources. The Agricultural Tourism Promotion Coordination Center (2004) has classified 6 types of agricultural tourism activities as follows:

1) Agro-tourism model in the form of show or demonstration, i.e. (1) demonstration plots of beautiful plant species such as orchids, flowering plants, local and foreign vegetables and fruits, (2) collection plots of various plant species. It is a collection of plant varieties from various sources such as banana varieties, durian varieties, mango varieties, (3) show the various agricultural practices such as raising, maintaining, and harvesting products, post-harvest care, packaging, product processing, beekeeping, silkworm farming, (4) performances of past agricultural cultural traditions such as seedlings, plowing, rice harvesting, fruit harvesting, fruit processing, handicrafts, and (5) displays of equipment, tools, utensils, and Thai agricultural methods in the past.

2) Agro-tourism model. Characteristics of tourists participating in short-term activities include (1) visiting an agricultural plantation by allowing tourists to collect produce from the trees in the garden or buying produce by choosing to collect themselves, which the tourists will be both beautiful. and natural atmosphere, (2) short-term local activities with villagers such as tapping tires, riding buffalo, wagon rides, boating, picking lotus flowers, etc. 


\section{International Journal of Current Science Research and Review}

ISSN: 2581-8341

Volume 04 Issue 09 September 2021

DOI: 10.47191/ijcsrr/V4-i9-03, Impact Factor: 5.825

IJCSRR@ 2021

Www.ijcsrr.org

3) Agro-tourism model in which tourists stay in villages or homestays. This is where tourists stay in villages to study and experience rural life by providing tourists with warm, safe, convenient, and clean services.

4) Agro-tourism model in the manner of educating new agriculture and knowledge that is the wisdom of the villagers as follows: (1) practice on modern farming such as planting, plant care, processing, and preserving agricultural products, etc., which may have certificates for tourists, (2) practice to learn local wisdom, such as studying insects or animals that are beneficial to agriculture, types, and benefits of local vegetables that can be eaten, how to make sugar from coconuts, massage, and herbal steam, etc.

5) Agro-tourism model in terms of selling agricultural products and products, namely (1) agricultural products and processing of housewives group, (2) local handicrafts from farmers, (3) household items and souvenirs, (4) fresh vegetables, fresh fruits, fresh flowers, (5) plants and seeds that tourists would buy and plant themselves, and (6) foods that produced and prepared in a simple but clean area, such as boiled corn, boiled beans, etc.

6) Agro-tourism model according to the nature of agribusiness avenues: (1) doing business or investing with farmers in relation to production or processing agricultural products for export or domestic sales, and (2) jointly produce and distribute various handicrafts.

In addition, the Office of Tourism Development Department of Tourism The Ministry of Tourism and Sports (2015) has also defined four components of the Agro-tourism Quality Standard as follows:

1) Component 1: Management potential of agro-tourism sites consists of 10 indicators: (1) Organizational Structure and Tourism Development Plan, (2) Formulation of a systematic area management plan, (3) Safety management safety, (4) waste management in tourist attractions, (5) acceptance and cooperation with surrounding communities, (6) networking to support tourist attractions, (7) conservation of natural resources and the environment, (8) maintenance of public utilities and tourism resources, (9) promotion, and (10) advertising and public relations of tourist attractions.

2) Component 2: Supporting potential of agricultural tourist attractions consists of 7 indicators: (1) the travel routes to the tourist attractions are comfortable and safe, (2) the availability of basic utilities, (3) the readiness of Accommodation for tourists, (4) food availability for tourists, (5) determining the number of tourists to suit the size of the area, (6) preparing personnel to accommodate tourists, and (7) determining the appropriate time for tourism.

3) Component 3: The service potential of agro-tourism sites consists of 9 indicators as follows: (1) hospitality and familiarity for tourists, (2) having a guide or tour leader, (3) selling daily necessities souvenirs, (4) diversity of activities in tourist attractions, (5) providing knowledge and information services of tourist attractions, (6) providing sightseeing vehicles for tourists, (7) contacting services communication for tourists, (8) provision of training and knowledge transfer, and (9) service for the elderly and disabled.

4) Component 4: Attraction potential of agricultural tourist attractions consists of 8 indicators as follows: (1) outstanding agricultural technology and specialized body of knowledge that is a model of agriculture, (2) distinction in the sufficiency economy and local wisdom, (3) natural conditions and beauty of tourist attractions, (4) connectivity of various types of tourist attractions within a radius of 20 kilometers, (5) receiving award or certificate from organizations or agencies related to agriculture or activities in tourism or local culture, (6) the distinctiveness and variety of agricultural products for sale for tourists, (7) the distinctiveness and variety of activities in tourist attractions, and (8) learning ways of life or participating in activities with farmers.

The study of Rakjing, et al. (2021) indicates that governments, such as local governments, play an important role in managing and standardizing the development and promotion of sustainable agro-tourism. In addition, the results of this study were analyzed to create a model for the promotion and development of agricultural tourism of local administrative organizations. The main 5 components of this model were found as shown in figure 2. 


\section{International Journal of Current Science Research and Review}

ISSN: 2581-8341

Volume 04 Issue 09 September 2021

DOI: 10.47191/ijcsrr/V4-i9-03, Impact Factor: 5.825

IJCSRR @ 2021

WWw.ijcsrr.org

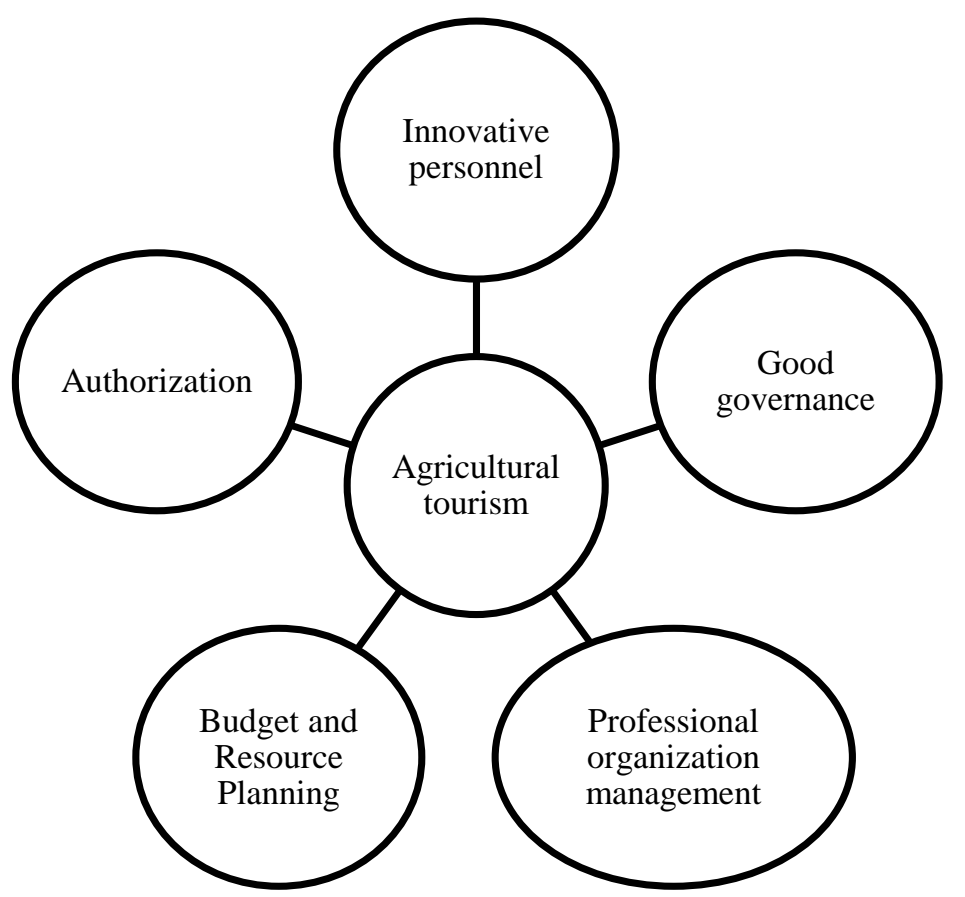

Figure 2. A model for the promotion and development of agricultural tourism

A study by Udomsilp, et al. (2020) who collected the data by interviewing and co-observation in an agro-tourism community in Nakhon Pathom Province, Thailand, found that such communities had potential in 5 components: physical and biological values, cognitive wisdom and innovation, tourism management, service in tourist areas, and tourist attraction. The results of a study on agrotourism in Thailand by Maraphot and Somboon (2016) suggested that the government should support and promote the community in the development of agro-tourism in many areas, such as co-planning with the tourism community, participating in community learning activities, restoring the landscape of the community to be beautiful and ready to accommodate tourists and to help promote agrotourism to tourists. The study of Pongwiritthon (2015) proposed the development guideline of sustainable agro-tourism that consisted of 3 main parts included (1) the pattern of Agro-Tourism had to be in form of community activities, (2) the pattern of sustainable Agro-tourism had to be appropriated by promoting the multi-choices of Agro-tourism pattern, and (3) searching for more opportunities to expand the market to increase the income. In addition, the study of Pansawang, et al. (2020) in marketing management to promote agricultural tourism in Thailand pointed out the 3 main factors included (1) creating cooperative networks with private and public organizations as well as local communities, (2) defining the local identities of attraction and activity, and (3) enhancing sustainable agro-tourism in focused areas.

\section{RESEARCH METHODOLOGY}

This research was participatory action research. Therefore, conducting research must involve the target community in every step of the work. In conducting this research, the process was as follows: (1) went to the area to assess the potential and readiness of the community in managing community-based tourism on an organic farming approach, (2) build an understanding of communitybased tourism and allow participants in the research process to jointly analyze their community well-being on issues of community history, occupational calendars, cultural calendars, and community beliefs, including local wisdom, maps of resources and the environment in the community, and local food and fruits. This is to enable the community to understand and recognize their own potential in community-based tourism management in an organic way, (3) take the Bankamkhonta community to study tourism management by other communities in order to give the Bankamkhonta community an opportunity to learn from direct experiences and real situations including learning success lessons and analyzing SWOT (Strength, Weakness, Opportunity, and Threat) as a guideline for further application in their communities, and (4) led the Bankamkhonta community together to create a tourism route 


\section{International Journal of Current Science Research and Review}

ISSN: 2581-8341

Volume 04 Issue 09 September 2021

DOI: 10.47191/ijcsrr/V4-i9-03, Impact Factor: 5.825

IJCSRR@ 2021

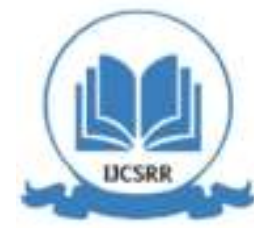

www.ijcsrr.org

by the Bankamkhonta community on the organic farming way. In the data analysis section, content analysis was used, including the validation of the data with a triple check (Triangulation) and the traceability of the informants (Member check) by allowing stakeholders in the research project to provide feedback with the results of data analysis in every process.

\section{RESEARCH RESULTS}

From the analysis of participatory research data, the results revealed that the Bankamkhonta community has the potential to manage community-based tourism based on the organic farming way. It can be regarded as a community with potential for community-based tourism resources such as organic rice farming, organic vegetable cultivation, organic product processing, forest resources and abundant community forests, and a source of safe food for people in the community especially the Dong Ma Fai National Reserved Forest and Don Pu Ta Community Forest. In addition, it was found that this community has the human resources to drive communitybased tourism work. It means the community is grouped together to drive concrete work in organic agriculture, such as community enterprises producing organic fertilizers and organic rice products, a group of cattle raisers, etc. In addition, there are other services that are ready to welcome tourists, such as safe accommodation, convenient transportation and routes.

The research findings from field visits in collecting data and collaborating with communities in SWOT analysis revealed that the Bankamkhonta community has strengths in integrated organic farming. This gives the community income for household expenses throughout the year. In addition, Yasothon province has a policy to promote the community to have organic farming under the vision "Yasothon is the organic farming city, The city of the Isan way" has resulted in the community being developed into a community that organizes community-based tourism on an organic way. But when considered in more detail, it was found that the Bankamkhonta community still had problems with debt issues, especially the debt of the Bank for Agriculture and Agricultural Cooperatives (BAAC). The community also had problems in environmental management and waste management in the community. And most importantly, the community still lacks a clear understanding of community-based tourism management.

The results of research in the area of development guidelines for Bankamkhonta community to become a tourist attraction by the organic farming community, it was found that Bankamkhonta has high potential to be developed as a tourist attraction area by the community. The research team worked together with the community to design a tourism route emphasizing activities that tourists have experienced and understand the value of organic agriculture (Organic Agro-Tourism) and eventually upgraded to Health \& Wellness Tourism. The organic farming tourism program at Bankamkhonta community is designed into 2 types, namely 1) One-day trip program and 2) 2 days 1-night program.

\section{DISCUSSION AND CONCLUSION}

From the research results, it was found that the Bankamkhonta community had the potential to manage community-based tourism based on organic agriculture. In other words, there are tourism resources and human resources to drive community performance, which can be achieved through the participation of researchers and community representatives in the search "Find good things for the community" in terms of way of life, living, community history, community sages, stories and beliefs in the community. Therefore, if considering the process of community development to become a tourist attraction by the community synthesized by Maneerot (2017) it can be considered as a preliminary feasibility study step. This is an important first step by considering the issue of community accessibility, tourism routes linking within the community and connecting areas within the community, the predominance of tourism resources that are local identity, exploring the physical characteristics of the area and linkage areas, and accessibility and tourism routes. The process of studying the potential of the community and the feasibility of tourism management is open to all sectors, formal and informal leaders, intellectual owners, community experts, community members, group members. Jointly survey and study the potential of tourism resources and community-based tourism facilities in detail, using the Criteria for Tourism by Community-Based Tourism Institute's accreditation criteria as a guideline for exploring and studying the potential. This includes documenting the physical characteristics of tourism resources in communities and connected areas, studying community history, narratives, myths, wisdom, the culture of groups that play a role in the community and community traditions, and studying connections between the community and the utilization of tourism resources in the area. Therefore, it can be seen that the Bankamkhonta community has enough potential to develop into a community that can manage tourism in an organic farming way. This is consistent with findings from several studies that indicate that, in the management of agro-tourism, it is necessary to have the potential to attract agro-tourism, to have a tourist attraction with a complete ecosystem, to be a tourist attraction with beautiful surroundings, naturalness, and a rural 


\section{International Journal of Current Science Research and Review}

ISSN: 2581-8341

Volume 04 Issue 09 September 2021

DOI: 10.47191/ijcsrr/V4-i9-03, Impact Factor: 5.825

IJCSRR@ 2021

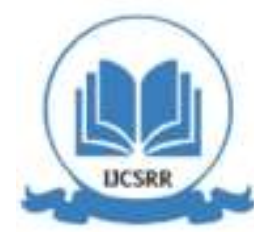

www.ijcsrr.org

way of life. At the same time, there must be a group or a committee using the process of participation in tourism management (Jussapalo, 2015; Intui, 2018; Maraphot \& Somboon, 2016).

Although the Bankamkhonta community has the potential to develop into a community that can manage tourism by the community, there are still a number of limitations that need to be developed and promoted, such as building a better understanding of tourism management. The problem of environmental management and waste in the community, which is a very important problem with some information about the community, is unclear or something is lost from the community. This is unfortunate and still has effects on tourism promotion that will occur in the future, such as the historical traces of the community being replaced by modern buildings, etc. By these things, the community should be developed, especially the development of human resources in various services to have professional skills, be a service-mindedness, be a good host, train the members to have deep knowledge, know the related things, and know the truth about the history of the community, traditions, wisdom, excursions in the community with a similar context to exchange ideas and experiences, and building a community tourism network (Maneerot, 2017).

For the community development according to the quality standards of agricultural tourist attractions, the Office of Tourism Development, Department of Tourism, The Ministry of Tourism and Sports (2015) has set four components of the quality standard of agricultural tourism attractions, namely: (1) management potential of agro-tourism sites that consists of organizational management structure, determination of agricultural tourism management, areas linked or cooperation with neighboring communities, with ready utilities, etc., (2) the potential of agricultural tourism attractions, which is ready to provide basic services for tourists, suitable for the environment of tourist attractions such as safety, ready utilities, (3) the service potential of agricultural tourist attractions such as having a local guide, shop in communities, various tourism activities, and (4) the attractive potential of agro-tourism sites such as natural conditions and beauty of tourist attractions, having natural beauty or being decorated in landscapes to be beautiful and harmonious with nature, Received awards, certificates or certificates from organizations or agencies related to agriculture, or activities related to tourism or the environment or local culture, such as the Kinnaree Award or the Green World Award, A logo of Agrotourism, GAP certificate from the Department of Agriculture Promotion, sufficiency economy and local wisdom localities such as agriculture in the new theory, natural or organic agriculture, biological production, etc.

On the issue of guidelines for community development of Bankamkhonta community as a tourist attraction by the organic farming community, it was found that the Bankamkhonta community had a high potential to be developed as a tourist attraction by the community. The research team has collaborated with the community to design a tourism route focusing on activities that tourists have experienced and understand the value of organic farming way (Organic agro-tourism) and may be upgraded to health tourism (Health \& Wellness Tourism). This result is consistent with the guidelines for the development of agro-tourism in the future suggested by Khermkhan (2018) which proposes to apply the new theory to the implementation of the development as a place for organic farming tourism. At present, it is found that business operations and agro-tourism operations can be successful throughout the year. Farmers must bring the new theory of agriculture into their operations by creating a tourist attraction in the style of organic agriculture, reducing the use of chemicals, using bio-fertilizers from composting scraps, branches, composts, manures, focusing on the farming integration because sticking to agricultural crops alone can be problematic due to climate variability and market variability. Farmers need community involvement by forming groups or parties at the local level to increase competitiveness, determine sales prices, and also contribute to employment and income distribution to local communities. The presence of government agencies to support and promote knowledge on tourism management and infrastructure to support the number of tourists in the future and to develop tourist attractions to be safe and convenient, and including receiving tourism awards to build standards and credibility for tourists. In addition, in line with the current tourism situation where agro-tourism is one of the important alternatives, the policies of the public and private sectors under the Pracharath Working Group has supported agro-tourism under the "Amazing Thai Taste" project, which is a project that encourages foreign tourists to consume more Thai food and Thai fruits.

\section{RECOMMENDATION}

From the research, it was found that Bankamkhonta village is a community with integrated organic farming, harvesting products throughout the year, and has budgets from many agencies to support the community's activities to drive organic farming. It was also found that the community had products that were widely known both inside and outside the province. Therefore, relevant agencies such as the Bank for Agriculture and Agricultural Cooperatives, the Office of Community Development, Provincial Tourism and Sports, etc., should come to promote, develop, extend and upgrade the community to become a community-based tourism community 


\section{International Journal of Current Science Research and Review}

ISSN: 2581-8341

Volume 04 Issue 09 September 2021

DOI: 10.47191/ijcsrr/V4-i9-03, Impact Factor: 5.825

IJCSRR@ 2021

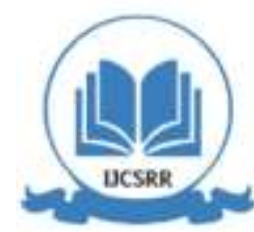

www.ijcsrr.org

in the organic farming way and become a community-based tourism community. Regarding recommendations for further research, the researcher suggested that 1) research should be conducted to assess the effectiveness of tourism routes proposed by the research team as a development guideline. Such research will provide useful and complete information to communities and agencies involved in the development of community-based tourism on the organic farming way of the Bankamkhonta community, and 2) there should be research to develop community-based tourism management on the organic farming approach to creative tourism in order to reduce restrictions from publicizing tourism routes according to the guidelines suggested by the research team for each activity.

\section{REFERENCES}

1. Agricultural Tourism Promotion Coordination Center. (2004). Handbook of Agricultural Tourism Administration and Management. Documents for the workshop on "Agro-tourism" management under the Thai Tourism and Agro-tourism Project in accordance with the measures to enhance rural and community development. (In Thai)

2. Chaisaengprateep, N. (2014). The formats and operation process of agro-tourism. Veridian E-Journal, 7 (3), 310-321. (In Thai)

3. Intui, J. (2018). Factors affecting decision making and expectation of Thai travelers on agro-tourism in Phitsanulok province. Master Degree of Science (Agribusiness), Kasetsart University, Thailand. (In Thai)

4. Jussapalo, S. (2015). Community-based agro-tourism management at South Bang Rieang Community, Khuan Nieng District, Sonkhla Province. Journal of Silpakorn University - Thai version, 35 (2), 89-103. (In Thai)

5. Khermkhan, J. (2018). The Perspective of Agro Tourism Development in Thailand. King Mongkut's Agricultural Journal, 36 (2), 162-167. (In Thai)

6. Khermkhan, J., Mankeb, P., \& Patthirasinsiri, N. (2018). Supply chain management for agro-tourism in Rayong province. Journal of the Association of Researchers, 23 (3), 98-109. (In Thai)

7. Maneerot, N. (2017). Community based tourism management. Journal of International and Thai Tourism, 13 (2), 25-46. (In Thai)

8. Manirochana, N., \& Nambuddee, N. (2020). The participatory action research in the experiential tourism management by the ethnic group community of Thai Puan living in Pak Phli, Nakhon Nayok province. Walailak Journal of Social Science, 13 (2), 499-522. (In Thai)

9. Maraphot, K. \& Somboon, T. (2016). The development of agro-tourism learning route: A case study of Tumbon Khlongkhuean, Chachoengsao province. Journal of Thai Hospitality and Tourism, 11 (2), 23-36. (In Thai)

10. Na Sonkhla, T. (2011). Relationship between Forms of Agro-tourism Activities and Usage of Local Agricultural Resources: A Case Study of Changklang Agro-tourism, Nakhon Si Thammarat Province. Journal of Management and Information, 6 (2), 310-321. (In Thai)

11. Pansawang, C., Wongmonta, S., Na Thalng, C., \& Pongponrat, K. (2020). Marketing management to promote agricultural tourism in Ratchaburi province. Journal of the Association of Researchers, 25 (3), 103-117. (In Thai)

12. Pongwiritthon, R. (2015). Development guidelines for sustainable agro-tourism: Pang Da Royal project. Suranaree Journal of Social Science, 9 (1), 19-35. (In Thai)

13. Rakjing, T., Toomhirun, C., Khlitong, J., \& Nillaor, P. (2021). Agro-tourism extension and development model by local administration organization. Journal of Social Science and Buddhistic Anthropology, 6 (5), 408-424. (In Thai)

14. The office of Tourism Development, Department of Tourism, Ministry of Tourism and Sports. (2015). Agro-tourism Quality Standards Assessment Manual. Retrieved on May 1 st, 2021 https://www.dot.go.th/ebooks/ebooks-view/422 (In Thai)

15. Udomsilp, M., Chadnok, P., Klomkumnerd, M., Saelim, S., \& Jamfah, A. (2020). Guidelines for Developing Community Based Tourism Activities to Connect Agrotourism at Huai Muang Subdistrict, Kamphaeng Saen District, Nakhon Pathom Province. The $12^{\text {th }}$ NPRU National academic conference, Nakhon Pathom, Thailand. (In Thai)

Cite this Article: Suthira Mankong, Amorn Chaisaen, Sahakuan Saentaweesook (2021). The Tourism Management in the Participatory Organic Farming Way at Bankamkhonta Village, Yasothon Province, Thailand. International Journal of Current Science Research and Review, 4(9), 1101-1107 